\title{
Perfil eletroforético das proteínas séricas de frangos de corte alimentados com dietas contendo aflatoxinas $\mathrm{e} / \mathrm{ou}$ argila clinoptilolita natural
}

\author{
Electrophoresis profile of serum proteins in broilers fed with diets containing aflatoxins and/or \\ natural clinoptilolite clay
}

\author{
Roberto Marinho Maciel ${ }^{I}$ Sonia Terezinha dos Anjos Lopes ${ }^{\text {II }}$ Janio Moraes Santurio ${ }^{\text {III }}$ \\ Alexandre Pires Rosa ${ }^{\mathrm{IV}}$ Marta Maria Medeiros Frescura Duarte ${ }^{\mathrm{V}}$ Danieli Brolo Martins ${ }^{\mathrm{I}}$ \\ Mauren Picada Emanuelli
}

\section{RESUMO}

O objetivo do presente trabalho foi avaliar o perfil eletroforético das proteínas séricas de frangos de corte alimentados com dietas contendo aflatoxinas e/ou argila clinoptilolita natural. Foram utilizados 528 frangos de corte, machos, da linhagem Ross, distribuídos em seis tratamentos com 4 repetições cada: $T 1$ - testemunha (ração sem aflatoxinas ou clinoptilolita), T2 - ração com 5ppm de aflatoxinas, T3 ração com 0,25\% de clinoptilolita, T4 - ração com 5ppm de aflatoxinas e 0,25\% de clinoptilolita, 55 - ração com 0,5\% de clinoptilolita e T6 - ração com 5ppm de aflatoxinas e 0,5\% de clinoptilolita. Os animais ficaram alojados em 24 boxes, e submetidos aos tratamentos do $1^{\circ}$ ao $42^{\circ}$ dia, quando foram sacrificados. Foram analisadas as proteínas totais, as frações albumina, alfa 1, alfa 2, beta e gama. Com exceção das médias da fração gama, o teste de Tukey revelou diferenças significativas $(P<0,05)$ nas médias de todas as proteínas totais e frações protéicas nos tratamentos onde as aflatoxinas estavam presentes. A ação das aflatoxinas nas proteínas totais ocorre na síntese de albumina e globulinas (frações alfa e beta). As gamaglobulinas não são afetadas pelas aflatoxinas. Em relação ao controle, as aves alimentadas com dietas com aflatoxinas $e$ clinoptilolita apresentaram baixos $(P<0,05)$ níveis de proteína total, albumina e globulinas (alfa e beta). Conclui-se que as aflatoxinas alteram o perfil eletroforético e que a clinoptilolita adicionada na ração não é capaz de evitar essas alterações.

Palavras-chave: proteínas séricas, clinoptilolita, aflatoxinas, frangos de corte, perfil eletroforético.

\section{ABSTRACT}

This study was aimed at evaluating the electrophoresis profile of serum protein in broilers fed with diets containing aflatoxins and natural clinoptilolite clay. Five hundred and twenty eight male broilers Ross were distributed in six treatments and each one with 4 replications: 11 - control (without aflatoxins or clinoptilolite), T2 -5ppm of aflatoxins, T3 -0.25\% of clinoptilolite, T4 -5ppm of aflatoxins and $0.25 \%$ of clinoptilolite, $T 5-0.5 \%$ of clinoptilolite and T6 - 5ppm of aflatoxins and $0.5 \%$ of clinoptilolite. The broilers were allocated in 24 boxes and submitted to a treatments for 42 days, when they were slaughtered. Total proteins, albumin fractions, alpha 1, alpha 2, beta and gamma were analyzed. Except gamma fraction the Tukey test showed differences $(P<0.05)$ on serum total proteins and proteins fractions in all treatments which aflatoxin was present. The clinoptilolite did not modify $(P<0.05)$ the serum proteins. The control broilers fed with diets containing aflatoxins and clinoptilolite presented low levels $(P<0.05)$ of total protein, albumin, and globulins (alpha and beta fractions). In conclusion, aflatoxins change the electrophoresis profile and clinoptilolite is not able to protect avoid these changes.

Key words: clinoptilolite, aflatoxin, broiler, electrophoresis profile.

\section{INTRODUÇÃO}

As aflatoxinas são micotoxinas produzidas por fungos do gênero Aspergillus, espécies A. flavus, A. parasiticus e A. nominus (MOSS, 1998). Os efeitos das aflatoxinas no organismo animal incluem carcinogenicidade, mutagenicidade, teratogenicidade e hepatotoxicidade (BRADBURN \& COKER, 1993).

A absorção de aflatoxinas ocorre por difusão passiva através do intestino, difundindo-se rapidamente por todos os tecidos do organismo

IPrograma de Pós-graduação em Medicina Veterinária, Universidade Federal de Santa Maria (UFSM), 97105-900, Santa Maria, RS, Brasil. E-mail: roberto.marinho@uol.com.br. Autor para correspondência.

${ }^{2}$ Departamento de Clínica de Pequenos Animais, UFSM, Santa Maria, RS, Brasil.

${ }^{3}$ Departamento de Microbiologia, UFSM, Santa Maria, RS, Brasil.

${ }^{4}$ Departamento de Zootecnia, UFSM, Santa Maria, RS, Brasil.

${ }_{5}^{5}$ Departamento de Análises Clínicas, Universidade de Cruz Alta (UNICRUZ), Cruz Alta, RS, Brasil. 
(RAMOS \& HERNANDEZ, 1996). Uma vez em contato com o tecido hepático, as aflatoxinas dão inicio à inibição da síntese protéica, o que resulta numa diminuição do nível de proteínas plasmáticas, principalmente da albumina e das globulinas alfa e beta (SANTIN, 2000). As aflatoxinas podem interagir com o DNA e o RNA nos hepatócitos dos mamíferos e das aves, formando um composto denominado AB1-DNA, quando se combinam com o DNA. A aflatoxina B1 causa uma inibição da síntese de DNA, correlacionada com a dose utilizada (ZAVIERO \& CONTRERAS, 2005).

A técnica da eletroforese permite a determinação das frações protéicas, na proporção em que são encontradas, no soro ou no plasma. As proteínas séricas se separam em um campo elétrico, em função de seus diferentes pontos isoelétricos. Após a coloração, essas bandas são escaneadas por um densitômetro e traduzidas em um traçado eletroforético. A interpretação da curva eletroforética permite o cálculo da porcentagem de participação de cada fração protéica (BUSH, 2004).

A albumina é uma proteína de alta densidade, sendo responsável pelo transporte de ácidos graxos, cálcio, magnésio, zinco, cobre, bilirrubina, ácido úrico, vitaminas $\mathrm{A}$ e $\mathrm{C}$, hormônios sexuais e, no caso específico das aves, dos hormônios tireoideanos. As beta-globulinas são constituídas em sua grande maioria por transferrina, uma glicoproteína responsável pelo controle da absorção do ferro no intestino e a sua distribuição no organismo. A ceruloplasmina é uma alfaglobulina responsável pelo transporte do cobre e que possui ação enzimática sobre as aminas, fenóis, enóis e íons ferrosos, através de processos de catalização (BACILA, 2003). As gama ou imunoglobulinas são produzidas pelos plasmócitos e linfócitos $\mathrm{B}$, presentes no tecido linfóide, sendo constituídas pelos anticorpos IgG, IgA, IgE, IgD e IgM (BUSH, 2004).

As argilas zeólitas podem ser usadas como adsorventes eficazes de agentes tóxicos, principalmente as aflatoxinas presentes na ração (PHILLIPS, 1999). As zeólitas são minerais, naturais ou sintéticos, que apresentam estrutura constituída por canais e cavidades interconectadas de dimensões moleculares. A clinoptilolita é uma das 40 espécies de zeólitas naturais conhecidas. A alta capacidade de absorção da clinoptilolita decorre de sua grande superfície interna, cerca de $300 \mathrm{~m}^{2} \mathrm{~g}^{-1}$ (LUZ, 1995).

A relação albumina/globulina nas aves é um indicador de alta significância clínica, para se avaliar a resposta inflamatória em caso de enfermidade (KANEKO, 1997). Na presença de infecções, as relações albumina/globulina se alteram, invertendo-se os valores pelo incremento que ocorre na concentração das imunoglobulinas (BACILA, 2003).

O presente trabalho teve como objetivo avaliar o perfil eletroforético das proteínas séricas totais de frangos de corte com 42 dias, alimentados com dietas com aflatoxinas, e testar o efeito protetor adsorvente da argila clinoptilolita na intoxicação experimental.

\section{MATERIAL E MÉTODOS}

Foram utilizadas 528 aves da linhagem Ross, machos, provenientes do incubatório do laboratório de Avicultura do Departamento de Zootecnia da Universidade Federal de Santa Maria (UFSM). As aves foram alojadas em 24 boxes, com 22 animais cada. Nos primeiros 21 dias, o período de luminosidade foi de 24 horas. A partir de então, a iluminação passou a ser apenas luz natural. Durante o experimento, a água foi fornecida à vontade. $\mathrm{O}$ fornecimento da ração foi realizado de acordo com a fase de desenvolvimento da ave (Tabela 1).

O desenho experimental foi inteiramente casualizado, com seis tratamentos e quatro repetições: (T1) Controle: dieta normal, (T2): dieta com 5ppm de aflatoxinas, (T3): dieta com $0,25 \%$ de clinoptilolita, (T4): dieta com 5pm de aflatoxinas mais $0,25 \%$ de clinoptilolita, (T5): dieta com $0,5 \%$ de clinoptilolita e (T6): dieta com $5 \mathrm{ppm}$ de aflatoxinas mais $0,5 \%$ de clinoptilolita.

As aflatoxinas utilizadas no experimento tinham a seguinte constituição: $80 \%$ B1, $12 \%$ B2, $5 \%$ G1 e 3\% G2, e foram produzidas pelo Laboratório de Pesquisas Micológicas (LAPEMI, UFSM), a partir da fermentação de Aspergillus parasiticus, cepa NRRL 2999 em arroz. O adsorvente clinoptilolita natural foi fornecido pelo LAPEMI.

Após 42 dias, foram retiradas, aleatoriamente, três aves de cada um dos 24 boxes. As 72 aves foram dessensibilizadas com corrente elétrica e imediatamente sacrificadas, sendo coletados, de cada animal, $10 \mathrm{~mL}$ de sangue, sem anticoagulante, por punção cardíaca. Após centrifugação, o soro obtido foi acondicionado e armazenado a $-20^{\circ} \mathrm{C}$ para posterior análise eletroforética das proteínas séricas.

A eletroforese foi realizada no Laboratório de Análises Clínicas LABIMED, localizado em Santa Maria, Rio Grande do Sul. As proteínas totais foram dosadas no analisador de química seca VITROS 950, a separação e a quantificação das frações das proteínas totais do soro foram realizadas pela técnica de eletroforese em fita de acetato de celulose, sendo a leitura e o cálculo do fracionamento eletroforético realizados no densitômetro para eletroforese $\mathrm{Z}-30 / \mathrm{C}$, 
Tabela 1 - Composição estimada das dietas basais da fase inicial, crescimento e final de frangos de corte.

\begin{tabular}{llll}
\hline & & Fases (dias) \\
\cline { 2 - 4 } Composição química & Inicial & Crescimento \\
\cline { 2 - 4 } & $1-21$ & $22-36$ & $36-42$ \\
\hline Proteína bruta (\%) & 22,00 & 20,00 & 20,00 \\
Energia metabolizável (kcal kg-1) & 3050 & 3100 & 3200 \\
Cálcio (\%) & 1,00 & 0,96 & 0,90 \\
Fósforo útil (\%) & 0,45 & 0,45 & 0,40 \\
Lisina (\%) & 1,30 & 1,17 & 1,10 \\
Metionina (\%) & 0,56 & 0,54 & 0,52 \\
Metionina + Cisteina (\%) & 0,92 & 0,89 & 0,88 \\
Treonina (\%) & 0,80 & 0,71 & 0,71 \\
Triptofano (\%) & 0,20 & 0,22 & 0,22 \\
\hline
\end{tabular}

com separação manual das frações protéicas: albumina, alfaglobulinas, betaglobulinas e gamaglobulinas.

Os dados obtidos foram analisados pelo GLM ANOVA do SAS. Eventuais diferenças significativas ao nível de 5\% foram comparadas pelo teste de Tukey.

\section{RESULTADOS E DISCUSSÃO}

As médias das proteínas totais e suas frações protéicas, encontradas no soro de frangos de corte com 42 dias e que receberam dietas com aflatoxinas e/ou clinoptilolita, estão expressas na tabela 2 .

$\mathrm{O}$ valor médio da proteína sérica total, encontrado no tratamento 1 , foi de $3,43 \mathrm{~g} \mathrm{dL}^{-1}$. Esse valor ficou próximo de $3,17 \mathrm{~g} \mathrm{dL}^{-1}$, encontrado, nas mesmas condições, tanto por BATINA et al. (2005), quanto por FRANCISCATO (2006), quando realizaram experimentos com aflatoxinas, na mesma espécie e sexo, porém utilizando raça e adsorvente diferentes. A adição de 5 ppm de aflatoxinas na ração resultou na redução de $51,90 \%$ na síntese de proteína total, o que expressa uma hipoproteinemia significante $(\mathrm{P}<0,05)$. BATINA et al. (2005), utilizando a mesma dose de aflatoxinas, observaram uma redução na síntese de proteína total de 33,69\%. Porém, FRANCISCATO (2006) observou um declínio de 44,79\% na síntese de proteína total, ao utilizar 3ppm de aflatoxinas. A redução no nível de proteínas totais, um dos principais efeitos das aflatoxinas, ocorre pela inibição da síntese protéica (SANTIN, 2000). As aflatoxinas têm a habilidade de se ligarem de forma covalente com constituintes intracelulares da célula hepática, principalmente DNA e RNA, comprometendo a síntese de proteínas (SANTURIO, 2000). Após uma hora da ingestão das aflatoxinas, já ocorre inibição na síntese protéica in vitro, devido à acentuada inibição da RNA-polimerase
(SANTIN, 2000). Os efeitos deletérios das aflatoxinas sobre a síntese de proteína não são explicados apenas pela dose de aflatoxinas utilizada. Fatores como desbalanceamento nutricional, erros de manejo, variações extremas na temperatura, condições das camas utilizadas, assim como a qualidade dos pintos alojados, têm grande importância na resposta das aves ao nível de aflatoxinas exposto (SANTURIO, 2000). Quanto maior o nível de estresse, menor será a dose de aflatoxinas necessária para comprometer o desempenho dos animais (DOERR et al., 1983).

As médias das proteínas totais, nos tratamentos em que foi adicionada clinoptilolita à ração, não sofreram variações significativas $(\mathrm{P}>0,05)$. Isso demonstra que a clinoptilolita utilizada como adsorvente, nas duas concentrações, foi inerte ao organismo durante sua permanência no trato gastrintestinal da ave, corroborando os dados de PAPAIOANNOU et al. (2004), quando citam que as dietas suplementadas com zeólitas são bem toleradas pelos animais.

A dose de aflatoxinas empregada está no intervalo de letalidade para a espécie: DL50 (2 a 6,3ppm). A adição da clinoptilolita, nas concentrações de 0,25 e $0,5 \%$, na ração contaminada com aflatoxinas, não demonstrou resultados significativos na proteção da síntese protéica $(\mathrm{P}>0,05)$.

A média da fração da albumina encontrada foi de $1,77 \mathrm{~g} \mathrm{dL}^{-1}$, o que representa $51,60 \%$ do total das proteínas séricas. As globulinas somam $1,66 \mathrm{~g} \mathrm{dL}^{-1}$, respondendo pelos $48,40 \%$ restantes. Esses resultados diferem de BATINAetal.(2005) eFRANCISCATO(2006) que utilizando métodos cinéticos para a análise bioquímica das proteínas, encontraram respectivamente médias de $1,26 \mathrm{~g} \mathrm{dL}^{-1}$ e $1,16 \mathrm{~g} \mathrm{dL}^{-1}$ para a albumina e de $2,45 \mathrm{~g} \mathrm{dL}^{-1} \mathrm{e} 2,01 \mathrm{~g} \mathrm{dL}^{-1}$ para as globulinas. Embora se trate de animais da mesma espécie, sexo e faixa etária, 
essas divergências são justificadas por RAVEL (1997), quando diz que as diferentes técnicas disponíveis para o fracionamento das proteínas séricas podem não fornecer valores idênticos para todas as frações protéicas ou proteínas individuais.

As alterações observadas nas concentrações de proteína total se devem primariamente a aumentos ou diminuições na concentração de albumina. As globulinas têm menor influência nessas variações (BUSH, 2004). A falta de aminoácidos essenciais à síntese, decorrente de uma desnutrição, pode concorrer para a diminuição dos níveis de albumina (RAVEL, 1997). O efeito das aflatoxinas nos frangos é maior na fase de crescimento, ou seja, durante os primeiros 21 dias (SANTURIO, 2000). A composição estimada das dietas basais nas 3 fases de desenvolvimento das aves é apresentada na tabela 1. Durante os primeiros 21 dias, a proporção de proteína disponível na ração foi a mais elevada. A ação das aflatoxinas foi mais acentuada na fração da albumina, que teve uma diminuição de $63,30 \%$ em sua concentração sérica, ao passar de $1,77 \mathrm{~g} \mathrm{dL}^{-1}$, observado no tratamento 1 , para $0,65 \mathrm{~g} \mathrm{dL}^{-1}$, verificado no tratamento 2. As observações de BATINA et al. (2005) indicam uma diminuição de $51,60 \%$ nos níveis de albumina sérica em relação ao controle. Já FRANCISCATO (2006) verificou uma diminuição sérica de 31,90\%, nessa mesma fração. A clinoptilolita, nas duas concentrações, não interferiu significativamente na ação das aflatoxinas, na síntese da albumina $(\mathrm{P}>0,05)$, como mostra a tabela 2.

A média das proteínas, observadas na fração das betaglobulinas, foi de $0,64 \mathrm{~g} \mathrm{dL}^{-1}$, o que corresponde a $18,70 \%$ das proteínas totais. A ação das aflatoxinas sobre a região das betaglobulinas levou a uma diminuição de 45,30\% nos seus níveis séricos $(\mathrm{P}<0,05)$. Essa diminuição pode comprometer o transporte do ferro no plasma (BACILA, 2003). Nas aves, o ferro plasmático se liga apenas à transferrina, sendo rapidamente transferido para as células eritróides da medula óssea. A transferrina também pode controlar a absorção de ferro no intestino e a sua distribuição no organismo. A média das betaglobulinas não inclui o fibrinogênio, que foi consumido na formação do coágulo. Embora a eletroforese possa ser realizada com o plasma sangüíneo, é muito mais indicado utilizar o soro, que não contém fibrinogênio, justamente porque a presença do fibrinogênio pode obscurecer a região de transição entre a fração das betaglobulinas e a fração das gamaglobulinas na curva eletroforética (THOMAS, 2000). Essa observação é reforçada por RAVEL (1997), quando diz que o fibrinogênio do sangue não totalmente coagulado pode produzir um pico, na região beta, simulando um pico monoclonal.

As alfaglobulinas participaram com $16,33 \%$ do total de proteínas séricas encontradas nesse experimento. $\mathrm{O}$ valor médio da fração alfa dois, $0,44 \mathrm{~g}$ $\mathrm{dL}^{-1}$, é quase 4 vezes maior que o valor médio da fração alfa um, 0,12\%. As aflatoxinas reduziram, significativamente $(\mathrm{P}<0,05)$, os níveis séricos nas duas frações de alfaglobulinas, sendo a média de 52,30\% na fração alfa dois e 50\% na fração alfa um. A diminuição das alfaglobulinas é verificada nos estádios finais da cirrose hepática (THOMAS, 2000). Tanto a haptoglobina quanto a ceruloplasmina, proteínas da fração alfa, estão diminuídas nas hepatopatias graves e estados de desnutrição (RAVEL, 1997). As aves submetidas às aflatoxinas tiveram uma redução de até $51,90 \%$ no peso corporal, em relação ao grupo controle.

A análise das gamaglobulinas revelou que o valor médio das mesmas é de $0,45 \mathrm{~g} \mathrm{dL}^{-1}$, o que corresponde à $13,12 \%$ do total das proteínas séricas. A presença das aflatoxinas provocou uma redução de 13,3\% no nível desses anticorpos, e a adição da clinoptilolita no tratamento 6 manteve a média da fração gama bem próxima à do controle, sem significância

Tabela 2 - Concentrações séricas de proteínas totais, albumina, alfaglobulina $1(\alpha 1)$, alfaglobulina 2 ( $\alpha$ 2), betaglobulina ( $\beta$ ), gamaglobulina $(\gamma)$ e relação albumina/globulina, verificadas em frangos de corte alimentados com dietas contendo aflatoxinas e/ou clinoptilolita natural.

\begin{tabular}{|c|c|c|c|c|c|c|c|c|c|}
\hline AFL ppm & CLI, \% & PRT, $\mathrm{g} \mathrm{dL}^{-1}$ & $\mathrm{ALB}, \mathrm{g} \mathrm{dL}^{-1}$ & GLO, $\mathrm{g} \mathrm{dL}^{-1}$ & $\mathrm{R}, \mathrm{A} / \mathrm{G}$ & $\alpha 1, \mathrm{~g} \mathrm{dL}^{-1}$ & $\alpha 2, \mathrm{~g} \mathrm{dL}^{-1}$ & $\beta, \mathrm{g} \mathrm{dL}^{-1}$ & $\gamma, \mathrm{g} \mathrm{dL}^{-1}$ \\
\hline 0 & 0 & $3,43 \pm 0,42^{\mathrm{a}}$ & $1,77 \pm 0,21^{\mathrm{a}}$ & $1,66 \pm 0,17^{\mathrm{a}}$ & $1,12 \pm 0,08^{\mathrm{a}}$ & $0,12 \pm 0,04^{\mathrm{ab}}$ & $0,44 \pm 0,16^{\mathrm{a}}$ & $0,64 \pm 0,13^{\mathrm{a}}$ & $0,45 \pm 0,21$ \\
\hline 5 & 0 & $1,65 \pm 0,78^{\mathrm{b}}$ & $0,65 \pm 0,38^{\mathrm{b}}$ & $1,00 \pm 0,19^{\mathrm{b}}$ & $0,62 \pm 0,05^{\mathrm{b}}$ & $0,06 \pm 0,05^{\mathrm{b}}$ & $0,21 \pm 0,12^{\mathrm{c}}$ & $0,35 \pm 0,14^{\mathrm{c}}$ & $0,39 \pm 0,18$ \\
\hline 0 & 0,25 & $3,36 \pm 0,40^{\mathrm{a}}$ & $1,75 \pm 0,14^{\mathrm{a}}$ & $1,61 \pm 0,09^{\text {ac }}$ & $1,11 \pm 0,03^{\mathrm{a}}$ & $0,16 \pm 0,07^{\mathrm{a}}$ & $0,37 \pm 0,09^{\mathrm{ab}}$ & $0,55 \pm 0,12^{\mathrm{ab}}$ & $0,53 \pm 0,23$ \\
\hline 5 & 0,25 & $1,65 \pm 0,88^{\mathrm{b}}$ & $0,70 \pm 0,50^{\mathrm{b}}$ & $0,95 \pm 0,17^{\mathrm{b}}$ & $0,68 \pm 0,09^{b}$ & $0,06 \pm 0,05^{\mathrm{b}}$ & $0,22 \pm 0,11^{\mathrm{c}}$ & $0,34 \pm 0,14^{\mathrm{c}}$ & $0,33 \pm 0,15$ \\
\hline 0 & 0,5 & $3,45 \pm 0,35^{\mathrm{a}}$ & $1,80 \pm 0,18^{\mathrm{a}}$ & $1,64 \pm 0,05^{\mathrm{a}}$ & $1,10 \pm 0,02^{\mathrm{a}}$ & $0,16 \pm 0,08^{\mathrm{a}}$ & $0,45 \pm 0,07^{\mathrm{a}}$ & $0,57 \pm 0,16^{\mathrm{ab}}$ & $0,46 \pm 0,15$ \\
\hline 5 & 0,5 & $2,01 \pm 0,76^{\mathrm{b}}$ & $0,82 \pm 0,36^{\mathrm{b}}$ & $1,19 \pm 0,19^{\mathrm{bc}}$ & $0,60 \pm 0,03^{\mathrm{b}}$ & $0,08 \pm 0,08^{b}$ & $0,25 \pm 0,11^{\mathrm{bc}}$ & $0,42 \pm 0,15^{\mathrm{bc}}$ & $0,44 \pm 0,20$ \\
\hline
\end{tabular}

Médias, nas colunas, seguidas de letras diferentes, são estatisticamente significativas $(\mathrm{P}<0,05)$ pelo teste de Tukey. AFL - aflatoxinas; CLI clinoptilolita; PRT - proteínas totais; GLO - globulinas; R - relação. 
( $\mathrm{P}>0,05)$. Esse resultado difere de MARIN et al. (2003), quando observaram que o nível das gamaglobulinas de aves expostas a $70 \mu \mathrm{g} \mathrm{kg}^{-1}$ de aflatoxinas sofreu uma elevação de $24,70 \%$, ao subir de $0,73 \mathrm{~g} \mathrm{dL}^{-1}$, no grupo controle, para $0,91 \mathrm{~g} \mathrm{dL}^{-1}$, no grupo com as aflatoxinas. Esses autores sugerem que o processo inflamatório decorrente da exposição a doses subclínicas de aflatoxinas tenha induzido um discreto aumento na fração das gamaglobulinas. A imunodepressão resultante da ação das aflatoxinas afeta a capacidade da ave em sintetizar anticorpos e substâncias humorais como o interferon, a citocina e as proteínas do sistema complemento, comprometendo a funcionalidade dos leucócitos (AZZAM \& GABAL, 1998). As aflatoxinas afetam o perfil imunológico, porém sem suprimir completamente a produção de anticorpos (ZAVIERO \& CONTRERAS, 2005). Estas alterações diminuem a capacidade do organismo em oferecer resistência às enfermidades, o que compromete as respostas produtivas do lote (PIER, 1992). Os efeitos das aflatoxinas ao sistema imunológico da ave expõem o animal a uma infinidade de doenças (SANTIN, 2000).

A relação albumina/globulina, conforme demonstrada na tabela 2 , foi de 1,2 , no tratamento 1 . Esse resultado é semelhante ao de MARIN et al. (2003), que encontrou 1,11, ao trabalhar com frangos de corte na mesma faixa etária. Com a adição de $5 \mathrm{ppm}$ de aflatoxinas, houve um declínio de $44,60 \%$ no índice da albumina/globulina. Essa diminuição na relação albumina/globulina tem origem nas diferentes variações observadas nas frações da albumina e das globulinas, o que comprova a ação das aflatoxinas no fígado, único local de síntese da albumina. As globulinas, que têm outras fontes de síntese, tiveram uma diminuição menos acentuada nos níveis séricos. A adição de clinoptilolita nas duas concentrações não alterou o índice da relação albumina/globulina, porque o adsorvente provavelmente não interferiu na síntese protéica.

\section{CONCLUSÕES}

A adição de 5ppm de aflatoxinas na dieta de frangos de corte diminui as proteínas séricas totais, a síntese de albumina e globulinas (frações alfa e beta), mas não afeta o nível das gamaglobulinas.

A adição de clinoptilolita na dieta de frangos de corte, nas concentrações de 0,25 e $0,5 \%$, não altera o perfil eletroforético das proteínas séricas totais.

A adição de $5 \mathrm{ppm}$ de aflatoxinas e clinoptilolita, nas concentrações de 0,25 e $0,5 \%$, nas dietas de frangos de corte, diminui as proteínas séricas totais, a síntese de albumina e globulinas (frações alfa e beta), mas não afeta o nível das gama globulinas.

\section{AGRADECIMENTOS}

Ao Laboratório de Análises Clínicas LABIMED, Santa Maria-RS; ao Setor de Avicultura do Departamento de Zootecnia da UFSM-RS; ao Laboratório de Pesquisas Micológicas LAPEMI, UFSM-RS e ao Laboratório de Patologia Clínica do Hospital Veterinário, UFSM-RS.

\section{REFERÊNCIAS}

AZZAM, A.H.; GABAL, M.A. Aflatoxin and immunity in layer hens. Avian Pathology, n.27, p.570-577, 1998.

BACILA, M. Bioquímica veterinária. São Paulo: Robe, 2003. 583p.

BATINA, P.N. et al. Efeitos da adição de montmorilonita sódica na dieta sobre o perfil bioquímico de frangos de corte intoxicados com aflatoxina. Ciência Rural, v.35, n.4, p.826$831,2005$.

BRADBURN, N.; COKER, R.D. Aflatoxin contamination in maize. Tropical Science, v.33, n.44, p.418-428, 1993.

BUSH, B.M. Interpretação de resultados laboratoriais para clínicos de pequenos animais. São Paulo: Roca, 2004. 376p.

DOERR, J.A. et al. Effects of low levels chronic aflatoxicosis in broiler chickens. Poultry Science, n.62, p.1971-1977, 1983.

FRANCISCATO, C. Avaliação dos minerais séricos e da função hepática de frangos de corte experimentalmente intoxicados com aflatoxina e submetidos a diferentes concentrações de montmorilonita sódica na dieta. 2006. 26f. Dissertação (Mestrado em Medicina Veterinária) - Curso de Pós-graduação em Medicina Veterinária, Universidade Federal de Santa Maria.

KANECO, J.J. Serum proteins and the dysproteinemias. In: KANECO, J.J. et al. Clinical biochemistry of domestic animals. 5.ed. San Diego: Academic, 1997. Cap.5, p.117-138.

LUZ, A.B. Zeólitas: propriedades e usos industriais. Série Tecnologia Mineral, n.68, p.4-28, 1995.

MARIN, F.P. et al. Aflatoxina B1, selenio y saccharomyces cerevisiae em la respuesta inmune de pollos de engorde em el estado zulia, venezuela. Revista Científica, v.13, n.5, p.360$370,2003$.

MOSS, M.O. Recent studies of micotoxins. Journal of Applied Microbiology, v.84, p.62S-76S, 1998.

PAPAIOANNOU, D.S. et al. A field study on the effect of dietary use of a clinoptilolite-rich tuff, alone or in combination with certain antimicrobials, on the health status and performance of weaned, growing and finishing pigs. Research in Veterinary Science, n.76, p.19-29, 2004.

PHILLIPS, T.D. Dietary clay in chemoprevention of aflatoxininduced disease. Toxicological Science, n.52, p.118-126, 1999.

PIER, A.C. Major biological consequences of aflatoxicosis in animal production. Journal of Animal Science, v.70, p.3964-3967, 1992. 
RAMOS, A.J.; HERNANDEZ, E. In situ absorption of aflatoxins in rats small intestine. Mycopathologia, v.134, p.27-30, 1996.

RAVEL, R. Laboratório clínico - aplicações clínicas dos dados laboratoriais. 6.ed. Rio de Janeiro: Guanabara Koogan, 1997. 616p.

SANTIN, E. Micotoxicoses. In: JÚNIOR, A.B.; MACARI, M. Doenças das aves. Campinas: FACTA, 2000. Cap.6, p.379387 .
SANTURIO, J.M. Micotoxinas e micotoxicoses na avicultura. Revista Brasileira de Ciência Avícola, v.2, n.1, 2000.

THOMAS, J.S. Protein electrophoresis. In: FELDMAN, B. F et al. Schalm's veterinary hematology. 5.ed. Philadelphia: Lippincott Williams \& Wilkins, 2000. Cap.135, p.899-903.

ZAVIERO, D.; CONTRERAS, M. Impacto de hongos y micotoxinas em las aves. Industria Avícola, Illinois, v.52, n.7, p.899-903, 2005 